\title{
Prognosis and risk factors of patients with upper urinary tract urothelial carcinoma and postoperative recurrence of bladder cancer in central China
}

Qingwei Wang ${ }^{1 *} \mathbb{D}$, Tao Zhang ${ }^{1}$, Junwei $\mathrm{Wu}^{1}$, Jianguo Wen ${ }^{1,2}$, Deshang Tao ${ }^{1}$, Tingxiang Wan ${ }^{1}$ and Wen Zhu ${ }^{1}$

\begin{abstract}
Background: To investigate the prognostic risk factors and postoperative recurrence of bladder cancer in patients with upper urinary tract urothelial carcinomas (UTUCS).

Methods: Data of 439 UTUC patients were retrospectively analyzed. Follow-up and analysis of smoking effects, consumption of traditional Chinese medicine containing aristolochic acid, history of bladder cancer, age, sex, presence or absence of diabetes mellitus (DM), metformin use, tumor characteristics (number, location, stage, grade), and open or laparoscopic surgery on the prognosis of UTUCs were performed. Cox proportional hazard regression analysis was performed to analyze the relationship between various factors and the postoperative survival rate. The survival rate was analyzed using the Kaplan-Meier method. Moreover, logistic regression analysis was performed to analyze the relationship between the above mentioned factors and postoperative recurrence of bladder cancer.

Results: Overall, 439 patients met, including 236 males (53.7\%) and 203 females (46.3\%), the criteria for the final statistical analysis, and the average age was 66.7 years. The 1-, 3-, and 5-year overall survival rates of 439 UTUC patients were 90.0, 76.4, and 67.7\%, respectively. The 5-year survival rates of T1, T2, T3, and T4 patients were 90.2\%, $78 \%, 43.8 \%$, and $18.5 \%$, respectively. Factors influencing the long-term survival rate of UTUC patients were smoking, taking traditional Chinese medicine containing aristolochic acid, history of bladder cancer, age, tumor size, tumor stage, tumor grade, and lymph node metastasis. The risk factors related to postoperative bladder cancer recurrence were advanced tumor stage, high grade tumor, preoperative ureteroscopy, ureteral urothelial carcinoma, no postoperative bladder perfusion chemotherapy and DM without metformin use.

Conclusions: Advanced tumor stage and presence of a high-grade tumor were risk factors for not only poor UTUC prognosis but also BC recurrence. In addition, preoperative ureteroscopy, ureteral urothelial carcinoma and DM without metformin use were high risk factors for $\mathrm{BC}$ recurrence, whereas regular postoperative bladder perfusion chemotherapy was a protective factor.
\end{abstract}

Keywords: Upper urinary tract urothelial carcinoma, Survival analysis, Bladder cancer recurrence, Prognostic factor, Risk factor

\footnotetext{
* Correspondence: qwwang@zzu.edu.cn

${ }^{1}$ Department of Urology, The First Affiliated Hospital of Zhengzhou

University, Zhengzhou 450052, Henan, China

Full list of author information is available at the end of the article
}

(c) The Author(s). 2019 Open Access This article is distributed under the terms of the Creative Commons Attribution 4.0 International License (http://creativecommons.org/licenses/by/4.0/), which permits unrestricted use, distribution, and reproduction in any medium, provided you give appropriate credit to the original author(s) and the source, provide a link to the Creative Commons license, and indicate if changes were made. The Creative Commons Public Domain Dedication waiver (http://creativecommons.org/publicdomain/zero/1.0/) applies to the data made available in this article, unless otherwise stated. 


\section{Background}

Upper urinary tract urothelial carcinoma (UTUC) is a relatively rare tumor, accounting for approximately $10 \%$ of all renal tumors and only $5 \%$ of all urothelial carcinomas [1, 2], with an estimated annual incidence of almost two cases per 100,000 inhabitants in Western countries. The epidemiology and disease presentation of UTUCs in the Chinese population, however, are quite different from those in Western populations. First, UTUCs account for $20-30 \%$ of all transitional cell carcinomas (TCCs) in China, which is more common than that in Western countries [3, 4]. Second, UTUCs are more common in women than in men, with a ratio of 1.3:1 [4]. Third, the incidence of renal pelvis urothelial carcinoma is twice more among Chinese populations than among Western populations. TCC of the ureter accounts for more than half of UTUCs $[5,6]$ and about $25 \%$ of all renal carcinomas in China [3]. Finally, contrary to findings in Western countries, UTUC with an advanced stage, large tumor size, and lymph node metastasis (LNM) are less likely to progress in female Chinese patients than in male Chinese patients [7]. This may be associated with diverse environmental factors, such as pure-arsenic exposure in drinking water and consumption of aristolochic acid in Chinese herbs [3, 8].

However, the epidemiology and biological characteristics of UTUCs in the Chinese population have not gained research focus, and data are limited. Moreover, it remains unclear whether the following factors are related to prognosis and postoperative recurrence of bladder cancer (BC) in UTUC patients: diabetes mellitus (DM), metformin use in DM patients, preoperative ureteroscopy, and location of UTUC. Currently, radical nephroureterectomy (RNU) is the gold standard for treating UTUCs [9]. The incidence of intravesical tumor recurrence after operation is $20-50 \%$ [10]. Notably, $44 \%$ of patients with $\mathrm{BC}$ recurrence have invasive disease ( $\geq$ pT1 stage), and $82-89 \%$ of BC recurrences occur within 2 years after RNU [11]. Hence, identifying high risk factors of $\mathrm{BC}$ recurrence after RNU is a major concern for UTUC patients.

Although a few studies have assessed predictive or risk factors of UTUCs and/or BC recurrence in Chinese people $[3,12]$, data were mainly obtained from the population of the North and Southeast of China, not from the central areas of China. Since the epidemiology and disease characteristics may be related to different areas, along with factors influencing survival and tumor recurrence remain controversial, we developed a database of UTUC in our region to investigate the prognostic risk factors of UTUC and $\mathrm{BC}$ recurrence in central China. We hope that our research will contribute to UTUC treatment options and reduce the risk of recurrence of $\mathrm{BC}$ after RNU.

\section{Methods}

\section{Subjects}

Data of patients with upper urinary tract tumors (UUTTs) from the Department of Urology of our hospital (the largest hospital in China, located in central China) were collected from March 2011 to February 2017. The inclusion criteria were as follows: 1. patients with unilateral UTUCs; 2. those who underwent RNU; 3. those with postoperative pathological confirmation of UTUC; and 4. those with complete clinical data and follow-up. The exclusion criteria were as follows: 1. patients with bilateral UTUC; 2 . those with a history of UTUC awaiting renal transplantation; 3. those who received conservative treatment or simple nephrectomy; and 4. those with incomplete or missing clinical data.

Finally, 481 patients with UUTTs were selected. Among them, 12 patients did not undergo RNU, 8 had incomplete clinical data, 11 were lost to follow-up, 5 had squamous cell carcinoma, 4 had adenocarcinoma, and 2 were diagnosed with sarcoma. Finally, 439 patients with UTUC were included in this study. All patients underwent RNU with bladder cuff resection, and each patient was confirmed as having UTUC based on pathological reports.

\section{Data records}

The collected clinical data of UTUC patients included smoking status, history of taking Chinese herbs containing aristolochic acid, history of $\mathrm{BC}, \mathrm{DM}$, and $\mathrm{DM}$ with/ without metformin use, age, sex, tumor characteristics (number, location, stage, grade, type), operation method, preoperative ureteroscopy, postoperative bladder perfusion chemotherapy, and $\mathrm{BC}$ recurrence (Table 1 ).

The criteria for identifying the influencing factors were as follows: a smoking index (number of cigarettes per day $\times$ years of smoking) above 200 was considered smoking. A history of taking Chinese medicine containing aristolochic acid was considered if at least 1 of the following criteria were met: 1) taking Chinese herbal medicine or Chinese patent medicine containing caulis aristolochiae manshuriensis; the duration of ingestion included the continuous use of caulis aristolochiae manshuriensis for $>15$ days or the discontinuous use for $>2$ months and 2) the continuous or intermittent use of other types of Chinese herbal or proprietary medicines containing aristolochic acid ingredients for $>6$ months. Those aged > 50 years were considered as advanced in age. A low tumor location indicated ureteral urothelial carcinoma (UUC). The tumor clinical staging was performed according to the American Joint Committee on Cancer (AJCC) 2002; the tumor grading was assessed based on the WHO pathological grading system of malignant urothelial cancer 2004. 
Table 1 The related prognostic influencing factors of UTUCs and the risk factors of bladder cancer recurrence in this study

\begin{tabular}{|c|c|c|}
\hline Influential factors & Classification & $\begin{array}{l}\text { No. of patients } \\
(\%)\end{array}$ \\
\hline \multirow[t]{2}{*}{ Sex } & Male & $236(53.7 \%)$ \\
\hline & Female & 203(46.3\%) \\
\hline \multirow[t]{2}{*}{ Age } & $<50 \mathrm{yr}$ & $132(30.1 \%)$ \\
\hline & $\geq 50 \mathrm{yr}$ & 307(69.9\%) \\
\hline \multirow[t]{2}{*}{ Smoking } & Yes & $204(46.5 \%)$ \\
\hline & No & $235(53.5 \%)$ \\
\hline \multirow[t]{2}{*}{ TCHAA } & Yes & 173(39.4\%) \\
\hline & No & $166(60.6 \%)$ \\
\hline \multirow[t]{2}{*}{ History of $B C$} & Yes & $95(9.2 \%)$ \\
\hline & No & $344(90.8 \%)$ \\
\hline \multirow[t]{2}{*}{ DM } & Yes & 133(30.3\%) \\
\hline & No & $306(69.7 \%)$ \\
\hline \multirow[t]{2}{*}{$\mathrm{DM}+$ metformin use } & Yes & $53(39.8 \%)$ \\
\hline & No & $80(60.2 \%)$ \\
\hline \multirow[t]{2}{*}{ Number of tumors } & Single & $278(63.3 \%)$ \\
\hline & Multiple & $161(36.7 \%)$ \\
\hline \multirow[t]{2}{*}{ Tumor location } & Renal pelvis & $253(57.6 \%)$ \\
\hline & Ureter & $140(42.4 \%)$ \\
\hline \multirow[t]{2}{*}{ Tumor stage } & $\mathrm{T} 1-\mathrm{T} 2$ & $246(56.0 \%)$ \\
\hline & T3-T4 & 193(44.0\%) \\
\hline Tumor size & $\begin{array}{l}<3 \mathrm{~cm} \\
\geq 3 \mathrm{~cm}\end{array}$ & $\begin{array}{l}255(58.1 \%) \\
184(41.9 \%)\end{array}$ \\
\hline \multirow[t]{2}{*}{ Tumor grade } & G1-G2 & $352(80.2 \%)$ \\
\hline & G3 & $87(19.8 \%)$ \\
\hline LNM & $\begin{array}{l}\text { Yes } \\
\text { No }\end{array}$ & $\begin{array}{l}86(19.6 \%) \\
353(80.4 \%)\end{array}$ \\
\hline \multirow{2}{*}{$\begin{array}{l}\text { Preoperative } \\
\text { Ureteroscopy }\end{array}$} & Yes & 139(31.7\%) \\
\hline & No & $300(68.3 \%)$ \\
\hline \multirow[t]{2}{*}{ Operation mode } & Laparoscopic surgery & $312(71.1 \%)$ \\
\hline & Open surgery & $127(28.9 \%)$ \\
\hline \multirow[t]{8}{*}{$\mathrm{BC}$ recurrence } & & $89(20.3 \%)$ \\
\hline & Renal pelvis carcinoma & $30(33.7 \%)$ \\
\hline & Ureteral carcinoma & $59(66.3 \%)$ \\
\hline & 242 cases of PBPC & $28(11.6 \%)$ \\
\hline & 197 cases of no PBPC & $61(31.0 \%)$ \\
\hline & $\mathrm{DM}$ & 63(70.9\%) \\
\hline & DM with Metformin use & 15(16.9\%) \\
\hline & $\begin{array}{l}\text { DM without metformin } \\
\text { use }\end{array}$ & 48(53.9\%) \\
\hline
\end{tabular}

THCAA taking Chinese herbs containing aristolochic acid, LNM lymph node metastasis, $P B P C$ postoperative bladder perfusion chemotherapy, DM diabetes mellitus, $B C$ bladder cancer

\section{Follow-up}

All patients were followed up regularly by telephone or internet contact, which was recorded in the electronic medical records (EMR) system of our hospital. Full-time urologists were responsible for following up patients according to the UTUC guidelines, and the patients were urged to undergo their medical examinations on time. All examination results during the follow-up period were recorded in detail. Postoperatively, cystoscopy was performed every 3 months within 2 years to assess for recurrence, then once every 6 months in the 3rd-4th year, and then once a year thereafter. During the follow-up time, other routine examinations, including blood routine tests, liver and kidney function tests, abdominal B-scan ultrasonography, chest X-ray every 6 months, and abdominal computed tomography (CT) once a year, were performed. Based on the treatment guidelines for UTUCs and patients' wishes, bladder perfusion chemotherapy following RNU for patients with UTUC was not a compulsory treatment. Depending on whether bladder instillation was performed after the operation, patients were divided into two groups: the perfusion group and the non-perfusion group. Perfusion was performed once a week for a maximum of 8 weeks and then once a month for 1 year following the operation. All data were recorded and monitored using the Jiahe EMR System. The survival rate, $\mathrm{BC}$ recurrence rate, and risk factors of $\mathrm{BC}$ recurrence were analyzed. The mortality and cause of death in the follow-up period were assessed based on data obtained from the family members, and the remaining data were obtained from the EMR system or the attending doctor.

\section{Statistical analysis}

Each influencing clinical factor was quantified (Table 1). A Cox proportional hazard regression model was used to evaluate the relationship between the risk factors and postoperative survival rate. Survival time was defined as the difference between follow-up time and operative time in months. The Kaplan-Meier method was used to analyze the survival rate. Furthermore, factors affecting postoperative $\mathrm{BC}$ recurrence were analyzed using a logistic regression model. SPSS 20.0 software was used to analyze the data, and a $P$ value $<0.05$ was considered statistically significant.

\section{Results}

Overall, 439 patients were included in the final statistical analysis. Among the 439 patients, 236 were males (53.7\%) and 203 were females (46.3\%), and the average age was 66.7 years. The follow-up period ranged from 18 to 84 months, with an average of 62.5 months. Factors included in the analysis are shown in Table 1 . Tumor-associated death, $\mathrm{BC}$ recurrence rate, survival rate, risk factors for UTUCs, and BC recurrence were analyzed to predict the prognosis of patients with UTUC. 


\section{Survival rate}

The 1-, 3-, and 5-year overall survival rates of the 439 patients were $90.0,76.4$, and $67.7 \%$, respectively. The 5 -year survival rates of patients with T1, T2, T3, and T4 were 90.2, 78, 43.8, and 18.5\%, respectively (Fig. 1).

\section{Effects of cox regression analysis on the prognosis of UTUCs}

Cox regression analysis was performed to eliminate confounding factors. Eight factors, namely smoking, consumption of Chinese medicine containing aristolochic acid, history of BC, age, tumor stage, tumor grade, tumor size, and LNM, had a significant effect on survival and were identified as prognostic factors $(P<0.05)$. This suggested that smoking, taking Chinese medicine containing aristolochic acid, history of $\mathrm{BC}$, older age, advanced tumor stage, high-grade tumors, larger tumors, and presence of LNM were risk factors of UTUC patients with poor prognosis. Sex, number of tumors, tumor location, DM, and mode of operation had no effect on the prognosis $(P>0.05)$. The results of the analysis of factors influencing survival time and prognosis are shown in Table 2.

\section{Analysis of risk factors of postoperative $\mathrm{BC}$ recurrence} Among the 439 patients, 89 (20.3\%) had BC recurrence, and their data were analyzed using the binary logistic regression model. We found that advanced tumor stage, presence of a high-grade tumor, preoperative ureteroscopy, DM without metformin use, and UUC were risk factors of postoperative $\mathrm{BC}$ recurrence. Patients with 1 or more than 1 of the risk factors were more likely to experience $\mathrm{BC}$ recurrence. Furthermore, regular postoperative bladder perfusion chemotherapy was a protective factor for recurrent $\mathrm{BC}$. The results of the analysis of high risk factors for postoperative $\mathrm{BC}$ recurrence are shown in Table 3.

\section{Discussion}

In this study, we found that smoking, consuming Chinese medicine containing aristolochic acid, history of $\mathrm{BC}$, old age, advanced tumor stage, presence of high-grade tumor, larger tumor size, and LNM were predictive factors for worse survival of UTUC. In addition, tumor stage, tumor grade, preoperative ureteroscopy, UUC, and DM without metformin use were risk factors of $\mathrm{BC}$ recurrence, whereas regular postoperative bladder perfusion chemotherapy and DM with metformin use were protective factors for $\mathrm{BC}$ relapse. Because the accurate prediction of the prognosis of UTUC patients could contribute to risk stratification and devising therapeutic options for urologists or oncologists, we analyzed each predictor in detail.

The incidence of UTUCs has been increasing each year, and $60 \%$ of UTUCs are found to have already

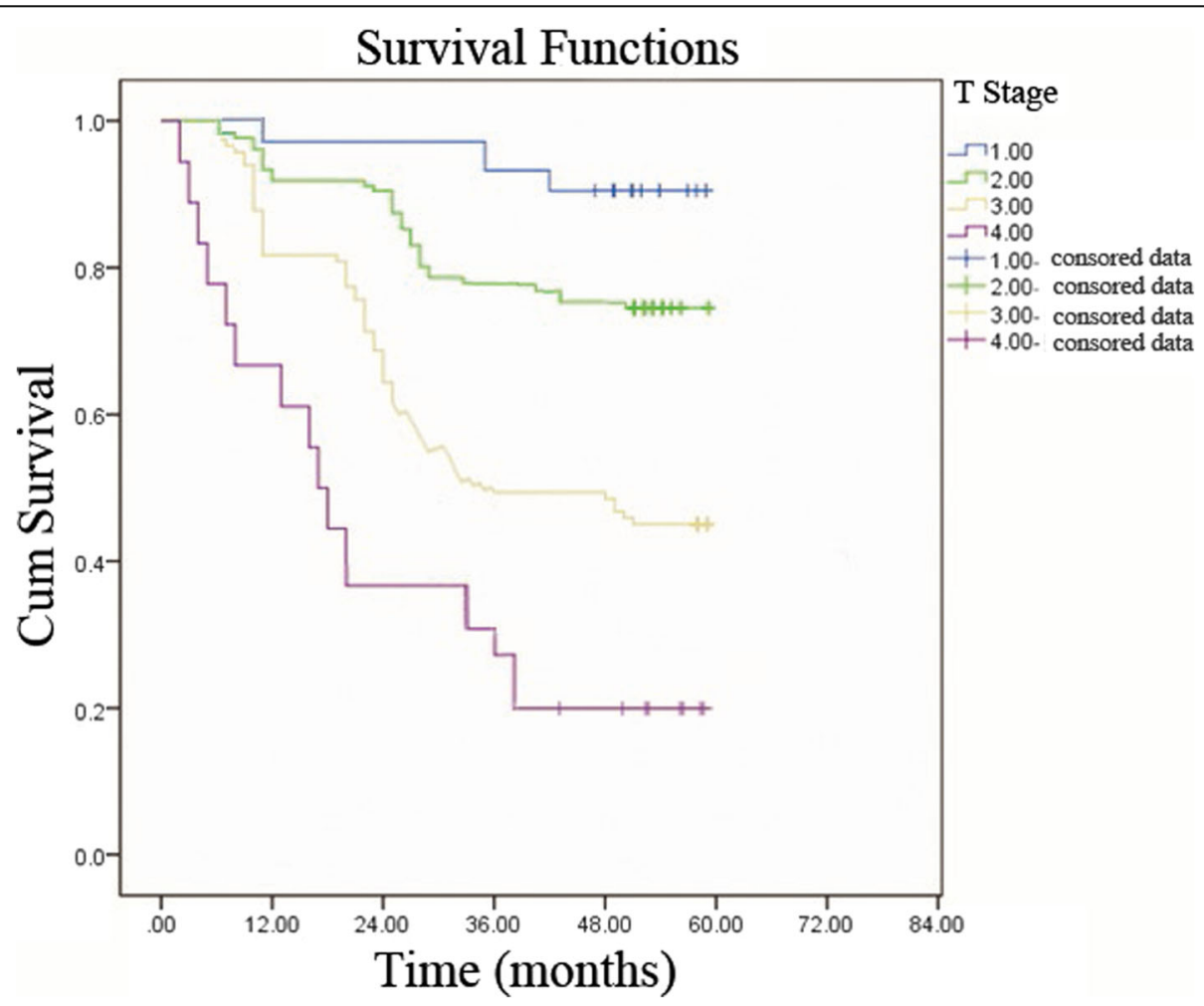

Fig. 1 The survival curve of the UTUC patients used by Kaplan-Meier method 
Table 2 The outcomes of multiple COX regression analysis in the prognosis of UTUC

\begin{tabular}{llllll}
\hline Variable & $\mathrm{B}$ & $\mathrm{SE}$ & Wald & $\operatorname{Exp}(\mathrm{B})$ & $\mathrm{P}$ \\
\hline Smoking & 0.964 & 0.214 & 20.207 & 2.381 & $<0.01$ \\
THCAA & 0.633 & 0.214 & 6.870 & 1.883 & 0.009 \\
Age & 0.357 & 0.169 & 4.468 & 0.700 & 0.035 \\
Sex & 0.002 & 0.145 & 0.000 & 1.002 & 0.991 \\
Number of tumors & 0.061 & 0.159 & 0.149 & 1.063 & 0.700 \\
History of BC & 0.698 & 0.228 & 9.356 & 2.010 & 0.002 \\
LNM & 1.994 & 0.353 & 31.915 & 7.343 & $<0.01$ \\
Tumor size & 0.449 & 0.158 & 8.086 & 0.638 & $<0.01$ \\
Tumor location & 0.162 & 0.260 & 0.390 & 0.850 & 0.532 \\
Tumor stage & 1.304 & 0.157 & 69.163 & 3.683 & $<0.01$ \\
Tumor grade & 2.157 & 0.298 & 52.291 & 8.646 & $<0.01$ \\
Operation mode & 0.472 & 0.378 & 1.559 & 1.603 & 0.212 \\
DM & 0.742 & 0.357 & 3.458 & 2.204 & 0.076 \\
\hline
\end{tabular}

THCAA taking Chinese herbs containing aristolochic acid, LNM lymph node metastasis, $D M$ diabetes mellitus

developed into invasive tumors at diagnosis compared with $15-25 \%$ of bladder tumors $[1,13]$. UTUCs have a peak incidence in individuals aged $70-90$ years and are three times more common in men in Western countries $[1,14]$; these findings differed from those of our study in which the male-to-female ratio was 1:1.16. Previous studies showed that the survival rate of UTUC patients was related to the tumor stage and grade [4]. A multifactorial analysis of 252 UTUC cases by Hall et al. [15] revealed that tumor stage was the only indicator of postoperative survival. A study of 434 patients with UTUCs by Munoz and Ellison [16] showed that the 5 -year survival rate of patients with Tis tumors was $95.1 \%$ and that of patients with local tumors was $88.9 \%$; however, the 5-year survival rate of patients with distant metastasis was only $16.5 \%$. In our study, tumor stage and grade were risk factors influencing the survival of postoperative UTUC patients. A significant difference in 5 -year survival rate occurred between low tumor staging (T1-T2) and high tumor staging (T3-T4), as well as between different tumor grades (G1-G2 and G3-G4). This suggests that early diagnosis and treatment with periodic follow-up are crucial for improving the survival rate.

UTUCs are prone to relapse and have a recurrence rate of $16-58 \%$ after surgery; thus, the current standard treatment of UTUCs is nephroureterectomy with bladder cuff resection [16]. The study also showed that the surgical approach (laparoscopic or open surgery) is not an influencing factor of postoperative survival. Mufti [17] also proposed that the surgical method (laparoscopy or open surgery) was not a prognostic factor, which is consistent with our results.

For most people, age is a risk factor of UTUC [18]. Raman et al. [19] investigated 13,800 patients with upper urinary tract tumors and showed that mortality owing to UTUCs increased with age. Similarly, we showed that compared with patients aged $<50$ years, the relative risk of postoperative mortality increased among patients aged $>50$ years. It is hypothesized that as the patient's age increases, the biological behavior of the tumor changes, with a decline in immune system function. LNM can be used to predict prognosis, especially for patients without lymph node dissection. Multicenter studies confirmed that LNM is closely related to higher tumor invasiveness, such as higher stage, higher grade, and distant metastasis. LNM can independently affect tumor recurrence and survival rate; hence, it is an independent risk factor for UTUC prognosis [20]. Our study also suggested that LNM was significantly associated with poor prognosis, which is consistent with the result of previous research. Tumor size has been also confirmed as a prognostic factor in some malignant tumors. The results of Simone's study [21] on UTUCs revealed that metastasis-free survival was closely related with tumor size: when the tumor diameter was $<3 \mathrm{~cm}$, there

Table 3 The results of multiple logistic regression analysis of recurrent BC after RNU in UTUC patients

\begin{tabular}{|c|c|c|c|c|c|}
\hline Variable & B & SE & Wald & $\operatorname{Exp}(B)$ & $P$ \\
\hline Age & 0.170 & 0.525 & 0.105 & 1.186 & 0.746 \\
\hline Operation mode Number of tumors & $\begin{array}{l}0.016 \\
0.030\end{array}$ & $\begin{array}{l}0.322 \\
0.389\end{array}$ & $\begin{array}{l}0.002 \\
0.006\end{array}$ & $\begin{array}{l}1.016 \\
1.030\end{array}$ & $\begin{array}{l}0.960 \\
0.939\end{array}$ \\
\hline LNM & 0.228 & 0.574 & 0.158 & 1.256 & 0.691 \\
\hline Advanced tumor stage & 1.064 & 0.300 & 12.548 & 2.899 & $<0.01$ \\
\hline Tumor location (UUC) & 2.835 & 0.627 & 20.440 & 16.949 & $<0.01$ \\
\hline High-grade tumor & 2.576 & 0.590 & 19.048 & 13.140 & $<0.01$ \\
\hline PBPC & -1.065 & 0.299 & 5.564 & 2.025 & 0.018 \\
\hline Preoperative Ureteroscopy & 1.010 & 0.290 & 7.920 & 11.292 & 0.003 \\
\hline DM without Metfoemin use & 2.156 & 0.354 & 6.785 & 3.872 & 0.032 \\
\hline
\end{tabular}

LNM lymph node metastasis, PBPC postoperative bladder perfusion chemotherapy, RUN radical nephroureterectomy, UUC ureteral urothelial carcinoma, DM diabetes mellitus 
was no metastasis within 5 years, whereas when it was > $3 \mathrm{~cm}$, the 5-year metastasis-free survival rate was $67 \%$. Our study also revealed that tumor size was a risk factor of UTUC, wherein a larger tumor diameter indicated worse prognosis.

It is known that smoking is a prognostic factor of UTUC. A study [22] revealed that smoking is the main risk factor of UTUC and lower urinary tract urothelial cancer. The incidence of urothelial carcinoma in smokers is three times greater than that in nonsmokers, probably owing to a mutation in tumor protein $\mathrm{p} 53$, chromosomal changes, immune regulation, etc. Our study also confirmed that smoking was a risk factor of poor prognosis in UTUC patients. Moreover, we found that consumption of herbal medicines such as Longdanxiegan pills, Paishi granule, Paishi decoction, and caulis aristolochiae manshuriensis, which contain aristolochic acid, also affected the prognosis of UTUC patients. DNA compounds can be formed in vivo under the influence of aristolochic acid [23], leading to the A-T base-pair proto-oncogene mutation, activation of RAS, and dysfunction of the cancer suppressor gene P53. Thus, smoking may play an important role in the occurrence of UTUCs. Additionally, our study confirmed that BC was a prognostic factor for UTUC, which is consistent with the findings of Nuhn [24]. This may be due to the similar pathogenesis of UTUC and BC or a missed diagnosis of UTUC in some BC patients (especially for ureteral TCCs). For the latter reason, urologists who examine patients with hematuria may often be satisfied with a BC diagnosis and omit ureteral TCCs that could also lead to $\mathrm{BC}$. This explains our finding that a prior history of muscle-invasive urothelial carcinoma of the bladder was significantly associated with an increased risk of disease recurrence and cancer-specific death in UTUC patients. Therefore, further adjuvant treatment, ureteroscopy, CT urography, and close follow-up should be performed after BC surgery.

It is generally believed that UTUC patients should be treated with radical RNU with the resection of bladder cuff resection [25]. However, the recurrence rate of $\mathrm{BC}$ is very high even after radical surgery. The incidence of $\mathrm{BC}$ relapse after operation in patients with TCC of the urinary tract is $30-70 \%$ [26], while the rate in our study was slightly lower at $20.3 \%$. In the case of postoperative $\mathrm{BC}$ recurrence, a tumor located in the ureter, especially at the lower end of the duct, is considered a high-risk factor for $\mathrm{BC}$ recurrence. Zigeuner [27] suggested that a ureteral tumor is prone to spread into the bladder because of its close anatomical position. This could be due to the mechanical stress caused by a higher urinary flow rate and larger chamber pressure, facilitating tumor cell metastasis. Furthermore, in recent years, studies worldwide have found that the risk of $\mathrm{BC}$ relapse in ureteral carcinoma is significantly higher than that of a renal pelvis carcinoma after RNU [28], which corresponds to the findings of our study. This, in some degree, supports the cancer cell implantation theory as the mechanism of $\mathrm{BC}$ recurrence. Fang et al. [28] analyzed the risk factors of $\mathrm{BC}$ recurrence after primary UTUC radical resection in 438 cases and found that high-grade ureteral cancer and multiple tumors were high-risk factors of $\mathrm{BC}$ recurrence. Therefore, a close follow-up with cystoscopy is necessary for patients with a high-grade, high-stage tumor and ureteral cancer (especially those with lower urinary tract ureteral cancer). These results indicate that tumor size and LNM are not independent risk factors of $\mathrm{BC}$ recurrence in UTUC patients after operation. However, there is limited research on whether tumor size and LNM affect bladder tumor recurrence; thus, more samples and multicenter studies are required.

Marchioni et al. [29] confirmed that preoperative ureteroscopy increases the risk of postoperative $\mathrm{BC}$ recurrence, which is consistent with the results our study. If the cancer cell implantation theory as the main mechanism of $\mathrm{BC}$ recurrence is accepted, there is greater risk of cancer cell exfoliation and implantation in the bladder after ureteroscopy examination. Thus, preoperative ureteroscopy should not be the primary and routine method for diagnosing UTUCs if imaging diagnosis is relatively clear; rather, a safer imaging method should be performed.

Because UTUC is closely related to BC and is associated with a higher $\mathrm{BC}$ recurrence rate, postoperative intravesical instillation chemotherapy has been widely used to prevent $\mathrm{BC}$ recurrence in postoperative UTUC patients. Many studies showed that postoperative bladder perfusion chemotherapy can effectively reduce the recurrence rate of BC after UTUC surgery [30]. Our study showed that postoperative bladder perfusion chemotherapy was a protective factor of $\mathrm{BC}$ recurrence after RNU. Therefore, UTUC patients could benefit from early diagnosis and regular postoperative intravesical instillation chemotherapy.

Recent studies have demonstrated that the incidence and mortality of tumor patients with DM were significantly higher than those of patients without DM. In this study, we found that UTUC patients with DM were more likely to experience $\mathrm{BC}$ recurrence. Among postoperative UTUC patients, the $\mathrm{BC}$ recurrence rate in those with DM was approximately four times that in patients without DM, and the result was significantly different. However, the specific mechanism remains unknown, which could be closely associated with DM itself and the associated hyperglycemia, hyperinsulinemia, and lipid metabolism disorder. In a study of 251 people with non-muscle-invasive bladder carcinoma, DM was an independent risk factor for disease recurrence [31]. Liu's in vitro experiments showed that high doses of insulin can promote the proliferation of urinary tract 
epithelial cells [32]. DM is often accompanied by insulin resistance and hyperinsulinemia; thus, Liu's study results may be a plausible explanation for easily recrudescent BC after surgery in UTUC patients with DM. Metformin is currently a first-line oral hypoglycemic drug for the treatment of type 2 DM. Currently, research has shown that metformin can reduce the risk of cancer by inhibiting the proliferation of tumor cells in vivo and in vitro $[33,34]$. Our study found that after RNU, the BC recurrence rate in UTUC patients with DM who did not take metformin was significantly higher than that in UTUC patients with DM who took metformin. Our study supported the fact that metformin can reduce the recurrence rate of BC in patients with UTUC and DM, which has not been reported thus far. Metformin mainly activates the AMPK pathway, promotes the expression of the P53 gene, and inhibits the mTOR pathway, thereby inhibiting tumor cell proliferation and reducing insulin and insulin-like growth factor levels [35]. However, whether these mechanisms also apply to the occurrence and progression of UTUCs in DM patients remain under study.

This study has some limitations. First, the research data represent a retrospective review of findings at a single center. Second, patients who were not surgically treated were not included in the analysis. Finally, lack of information on molecular biomarkers may reduce the strength of the findings. Therefore, further studies are necessary to confirm the role of molecular biomarkers as predictors for worse pathological outcomes of UTUCs.

\section{Conclusions}

In this study, the 5-year survival rate of UTUC patients from central China was not high compared with that of UTUC patients from other regions. We found that advanced tumor stage and presence of a high-grade tumor were risk factors for not only poor UTUC prognosis but also $\mathrm{BC}$ recurrence. In addition, preoperative ureteroscopy and DM without metformin use were high risk factors for $\mathrm{BC}$ recurrence, whereas postoperative bladder perfusion chemotherapy was a protective factor. Therefore, we suggest that UTUC patients with the above risk factors for $\mathrm{BC}$ recurrence should compulsorily undergo regular bladder perfusion chemotherapy. In addition, we suggest that preoperative ureteroscopy should not be exercised except when preoperative imaging diagnosis is difficult.

\footnotetext{
Abbreviations

BC: bladder cancer; CT: computed tomography; DM: diabetes mellitus; EMR: electronic medical records; LNM: Iymph node metastasis; RNU: radical nephroureterectomy; TCC: transitional cell carcinomas; TCCs: transitional cell carcinomas; UTUC: upper urinary tract urothelial carcinoma; UTUCs: upper urinary tract urothelial carcinomas; UUC: ureteral urothelial carcinoma; UUTT: upper urinary tract tumor
}

\section{Acknowledgements}

We thank statistician Xiaoping Shang, the member of medical records room in the First Affiliated Hospital of Zhengzhou University for offering the important help, and we thank Editage editing company for polishing the language as well.

\section{Funding}

This research was funded by the General Fund of scientific and technological project of Henan provincial Health Department (Number: 201602008). The fund body provided financial support in design of the study and collection, analysis, and interpretation of data.

\section{Availability of data and materials}

The datasets used and/or analyzed during the current study are available from the corresponding author on reasonable request.

\section{Authors' contributions}

WQ made substantial contributions to conception and design this study, revise it critically for important intellectual content, and give final approval of the version to be published. ZT and WJ1 (Junwei Wu) were involved in drafting the manuscript. WJ2 (Jianguo Wen) made substantial contributions to conception and design this study. TD, WT and ZW made substantial contributions to acquisition of data, analysis and interpretation of data. All authors have read the manuscript and approved its publication.

\section{Ethics approval and consent to participate}

This research adopted the retrospective analysis based on the principle of safety and fairness. The diagnosis and treatment conducted had no harm on the health of the subjects, and there was no risk for the subjects. All subjects signed the informed consent and their personal information would not be disclosed. Moreover, the research was beneficial and instructive for clinical practice. Based on the discussion of the medical scientific ethical committee of the First affiliated hospital of Zhengzhou University, this study was approved.

\section{Consent for publication}

Not applicable.

\section{Competing interests}

The authors declare that they have no competing interests.

\section{Publisher's Note}

Springer Nature remains neutral with regard to jurisdictional claims in published maps and institutional affiliations.

\section{Author details}

${ }^{1}$ Department of Urology, The First Affiliated Hospital of Zhengzhou University, Zhengzhou 450052, Henan, China. ${ }^{2}$ Department of Pediatric Surgery, The First Affiliated Hospital of Xinxiang Medical University, Xinxiang 453100, Henan, China.

Received: 9 November 2018 Accepted: 9 April 2019

Published online: 18 April 2019

\section{References}

1. Roupret M, Babjuk M, Comperat $E$, et al. European association of urology guidelines on upper urinary tract urothelial cell carcinoma:2015 update. Eur Urol. 2015;68(5):868-79.

2. Siegel RL, Miller KD, Jemal A. Cancer statistics, 2017. CA Cancer J Clin. 2017; 67(1):7-30.

3. Chen XP, Xiong GY, Li XS, Matin SF, et al. Predictive factors for worse pathological outcomes of upper tract urothelial carcinoma: experience from a nationwide high-volume Centre in China. BJU Int. 2013;112(7):917-24.

4. Chou $\mathrm{YH}$, Huang $\mathrm{CH}$. Unusual clinical presentation of upper urothelial carcinoma in Taiwan. Cancer. 1999;85(6):1342-4.

5. Yang $\mathrm{MH}$, Chen KK, Yen CC, et al. Unusually high incidence of upper tract urothelial carcinoma in Taiwan. Urology. 2002;59(5):681-7.

6. Li CC, Chang TH, Wu WJ, et al. Significant predictive factors for prognosis of primary upper urinary tract cancer after radical nephroureterectomy in Taiwanese patients. Eur Urol. 2008;54(5):1127-35.

7. Lughezzani G, Sun M, Perrotte $P$, et al. Gender-related differences in patients with stage I to III upper tract urothelial carcinoma: results from the surveillance, epidemiology, and end results database. Urology. 2010;75(2): $321-7$. 
8. Rouprêt M, Babjuk M, Compérat E, et al. European Association of Urology guidelines on upper urinary tract urothelial carcinoma: 2017 update. Eur Urol. 2018;73(1):111-22.

9. Iborra I, Solsona E, Casanova J, Ricos JV, Rubio J, Climent MA. Conservative elective treatment of upper urinary tract tumors: a multivariate analysis of prognostic factors for recurrence and progression. J Urol. 2003;169(1):82-5.

10. Keeley FJ, Bibbo M, Bagley DH. Ureteroscopic treatment and surveillance of upper urinary tract transitional cell carcinoma. J Urol. 1997;157(5):1560-5.

11. Ku JH, Choi WS, Kwak C, Kim HH. Bladder cancer after nephroureterectomy in patients with urothelial carcinoma of the upper urinary tract. Urol Oncol. 2011;29(4):383-7.

12. Wu YP, Lin YZ, Lin MY, et al. Risk factors for bladder Cancer recurrence survival in patients with upper-tract urothelial carcinoma. Tumori. 2017: tj5000705.

13. Margulis V, Shariat SF, Matin SF, et al. Outcomes of radical nephroureterectomy: a series from the upper tract urothelial carcinoma collaboration. Cancer. 2009:115(6):1224-33.

14. Shariat SF, Favaretto RL, Gupta A, et al. Gender differences in radical nephroureterectomy for upper tract urothelial carcinoma. World J Urol. 2011;29(4):481-6.

15. Hall MC, Womack S, Sagalowsky Al, Carmody T, Erickstad MD, Roehrborn CG. Prognostic factors, recurrence, and survival in transitional cell carcinoma of the upper urinary tract: a 30-year experience in 252 patients. Urology. 1998;52(4):594-601.

16. Brown GA, Busby JE, Wood CG, et al. Nephroureterectomy for treating upper urinary tract transitional cell carcinoma: time to change the treatment paradigm? BJU Int. 2006;98(6):1176-80.

17. Matsui $Y$, Utsunomiya N, Ichioka $K$, et al. Risk factors for subsequent development of bladder cancer after primary transitional cell carcinoma of the upper urinary tract. Urology. 2005;65(2):279-83.

18. Liu JY, Li YH, Zhang ZL, et al. Age-specific effect of gender on upper tract urothelial carcinoma outcomes. Med Oncol. 2013;30(3):640.

19. Raman JD, Messer J, Sielatycki JA, Hollenbeak CS. Incidence and survival of patients with carcinoma of the ureter and renal pelvis in the USA, 19732005. BJU Int. 2011;107(7):1059-64.

20. Simone G, Papalia R, Loreto A. Et al. independent prognostic value of tumour diameter and tumour necrosis in upper urinary tract urothelial carcinoma. BJU Int. 2009:103(8):1052-7.

21. Novara G, Matsumoto K, Kassouf W. Et al. prognostic role of lymphovascular invasion in patients with urothelial carcinoma of the upper urinary tract:an international validation study. Eur Urol. 2010;57(6):1064-71.

22. Hartge $P$, Silverman D, Hoover R, et al. Changing cigarette habits and bladder cancer risk: a case-control study. J Natl Cancer Inst. 1987;78(6):1119-25.

23. Lord GM, Hollstein M, Arlt VM, et al. DNA adducts and p53 mutations in a patient with aristolochic acid-associated nephropathy. Am J Kidney Dis. 2004:43(4):e11-7.

24. Nuhn P, Novara G, Seitz C, et al. Prognostic value of prior history of urothelial carcinoma of the bladder in patients with upper urinary tract urothelial carcinoma: resulrs from a retrospective multicenter study. World J Urol. 2015;33(7):1005-13.

25. Rongyao $L$, Peng $Z$, Xuesong $L$, et al. Transperitoneal laparoscopic complete nephrectomy for upper urinary tract urothelial carcinoma. Beijing Da Xue Xue Bao. 2011;43(4):531-4.

26. Hisataki T, Miyao N, Masumori N, et al. Risk factors for the development of bladder cancer after upper tract urothelial cancer. Urology. 2000:55(5):663-7.

27. Zigeuner RE, Hutterer G, Chromecki T, Rehak P, Langner C. Bladder tumour development after urothelial carcinoma of the upper urinary tract is related to primary tumour location. BJU Int. 2006;98(6):1181-6.

28. Fang $D$, Xiong GY, Li XS, et al. Pattern and risk factors of intravesical recurrence after nephroureterectomy for upper tract urothelial carcinoma: a large Chinese center experience. J Formos Med Assoc. 2014;113(11):820-7.

29. Marchioni M, Giulia P, Luca C, et al. Impact of diagnostic ureteroscopy on intravesical recurrence in patients undergoing radical nephroureterectomy for upper tract urothelial cancer: a systematic review and meta-analysis. BJU Int. 2017;120(3):313-9.

30. Raman JD, Ng CK, Boorjian SA, Vaughan EJ, Sosa RE, Scherr DS. Bladder cancer after managing upper urinary tract transitional cell carcinoma: predictive factors and pathology. BJU Int. 2005;96(7):1031-5.

31. Hwang EC, Kim YJ, Hwang IS, et al. Impact of diabetes mellitus on recurrence and progression in patients with non-muscle invasive bladder carcinoma:a retrospective cohort study. Int J Urol. 2011;18(11):769-76.
32. Liu S, Li Y, Lin T, Fan X, Liang Y, Heemann U. High dose human insulin and insulin glargine promote T24 bladder cancer cell proliferation via P13K-independent activation of Akt. Diabetes Res Clin Praet. 2011;91(2): $177-82$

33. Rattan R, Graham RP, Maguire JL, Giri S, Shridhar V. Mefformin suppresses ovarian cancer growth and metastasis with enhancement of cisplatin cytotoxicity in vivo. Neoplasia. 2011;13(5):483-91.

34. Gotlieb WH, Saumet J, Beauchamp MC, et al. In vitro metforminanti-neoplastic activity in epithelial ovarian cancer. Gynecol Oncol. 2008;110(2):246-50

35. Jalving $M$, Gietema JA, Lefrandt JD, et al. Metformin:taking away the candyfor cancer. EurJ Cancer. 2010;46(13):2369-80.
Ready to submit your research? Choose BMC and benefit from:

- fast, convenient online submission

- thorough peer review by experienced researchers in your field

- rapid publication on acceptance

- support for research data, including large and complex data types

- gold Open Access which fosters wider collaboration and increased citations

- maximum visibility for your research: over $100 \mathrm{M}$ website views per year

At $\mathrm{BMC}$, research is always in progress.

Learn more biomedcentral.com/submissions 